\title{
Menuju Pembukuan Secara Akuntabel dan Konsisten
}

\author{
Listya Sugiyarti ${ }^{1}$, Effriyanti ${ }^{2}$, \\ a,bProdi S1 Akuntansi, Fakultas Ekonomi, Universitas Pamulang* \\ Ilistya.sugiarti@unpam.ac.id; ${ }^{2}$ effriyanti.kurniawan@gmail.com \\ * listya.sugiarti@unpam.ac.id
}

\begin{abstract}
Abstrak
Pengabdian kepada masyarakat oleh dosen maupun civitas akademisi yang memiliki keilmuan mumpuni dapat dilakukan kepada masyarakat pada level apapun, dengan tujuan memberikan solusi permasalahan yang dihadapai dengan tujuan improvement kedepannya. Adapun tujuan dari kegiatan pengabdian kepada masyarakat di playgroup \& kindergarten Little Bee House dengan konsep "Home me" dengan sasaran peserta nya adalah komite POMG (Persatuan Orang Tua Murid dan Guru) dalam mengatasi permasalahan mengatur dokumentasi kegiatan-kegiatan yang sudah dilakukan baik dalam bentuk hard file maupun soft file dan pencatatan laporan keuangan dengan pembukuan secara akuntabel dan konsisten. Kegiatan dalam pelaksanaan pengabdian kepada masyarakat ini dengan tema Menuju Pembukuan Secara Akuntabel dan Konsiseten. Kegiatan pengabdian yang dilakukan oleh dosen Prodi S1 Akuntansi Universitas Pamulang pada tanggal 13-15 Oktober 2019 disambut baik oleh kepala sekolah Little Bee House dan para orang tua yang terlibat dalam kepengurusan POMG. Dengan menggunakan metode penyuluhan dan pendampingan, kegiatan ini sangat efektif dalam bentuk waktu dan penerimaan materi, kegiatan ini selain diadakan di indoor juga dilakukan di lokasi outdoor yang tujuannya agar dapat menyerap ilmunya lebih cepat dan memiliki semangat yang lebih. Dengan pembukuan yang diterapkan selama ini secara manual dan rata-rata pendidikan pengurus POMG adalah level strata 1, membuktikan bahwa mereka butuh mentor yang berkelanjutan. Respon para peserta sangat baik dan senang karena sangat terbantu dalam pembelajaran tentang mengatur dokumentasi dan pencatatan pembukuan keuangan secara akuntabel. Kegiatan ini diharapkan dapat memberikan inspirasi dan motivasi bagi para dosen/peneliti selanjutnya yang akan melakukan kegiatan yang sama/sejenis dan berkelanjutan, ilmu yang diberikan dapat bermanfaat bagi masyarakat, akademisi dan penulis selanjutnya.
\end{abstract}

Kata-kata kunci: Pembukuan secara Akuntabel, Konsiten, Dokumentasi.

\section{Abstract}

Community service by lecturers and academics who have qualified knowledge can be done to the public at any level, to provide solutions to problems faced with the aim of future improvement. The purpose of community service activities in the playgroup \& kindergarten Little Bee House with the concept of "Home me" with the target participants is the POMG committee (Association of Parents and Teachers) in overcoming the problem of organizing documentation of activities that have been carried out both in hard form files and soft files and recording of financial statements in an accountable and consistent manner. Activities in the implementation of community service with the theme Towards Bookkeeping Accountably and Consistently. Dedication activities carried out by the S1 Accounting Study Program of Pamulang University lecturers on October 13-15, 2019 were welcomed by the headmaster of Little Bee House and parents involved in the management of POMG. By using counseling and mentoring 


\begin{abstract}
methods, this activity is very effective in the form of time and material reception, besides being held indoors, this activity is also carried out in outdoor locations to absorb knowledge more quickly and have more enthusiasm. With the bookkeeping applied so far manually and the average education level of the POMG management is strata 1 level, proving that they need a sustainable mentor. The response of the participants was very good and happy because it was very helpful in learning about managing the accounting and recording of financial accounting in an accountable manner. This activity is expected to provide inspiration and motivation for future lecturers/researchers who will carry out the same/similar and sustainable activities, the knowledge provided can benefit the community, academics, and subsequent writers. .
\end{abstract}

\title{
Keywords: Accountable Bookkeeping; consitent; documentation
}

\section{PENDAHULUAN}

Pendidikan melalui formal dalam organisasi sekolah tidak terlepas dari dukungan sekolah itu sendiri, guru, para orang tua dan masyarakat sekitar. Playgroup dan Kindergarten Little Bee House Pamulang salah satu di antara sekolah yang berada di Permata Pamulang, Rawakalong, Tangerang Selatan. Keberadaan Little Bee House yang memiliki konsep sekolah "home me" membantu para orang tua sekitar daerah perumahan Permata Pamulang untuk mendapatkan solusi agar anak mereka dapat bersekolah tidak jauh dari rumah mereka sendiri dan memiliki kualitas yang bagus, dan bagi orang tua yang tidak tinggal di perumahan Permata Pamulang masih menjangkau lokasi yang strategis dari berbagai penjuru (masih sekitar pamulang dan bogor). Karena Little Bee House Pamulang ini berada di perumahan Permata Pamulang, di mana perumahan ini berbatasan dengan daerah bogor. Sejak berdirinya sekolahini tiga tahun yang lalu, jumlah murid bertambah terus hingga pihak sekolah menambah bangunan sekolahnya yang masih disekitar perumahan tersebut. Artinya PMOG dan sekolahan sudah dipercaya oleh masyarakat, hanya dengan kepercayaan tersebut harus menjadi organisasi yang lebih baik lagi.

Playgroup \& kindergarten dengan konsep "Home $m e$ ” adalah salah satu keunggulan dari sekolah ini jika para orang tua menginginkan anaknya bersekolah dengan suasana seperti di rumah sendiri dan nyaman. Konsep yang dibuat oleh sekolah harus didukung oleh keberadaan orang tua maupun sekeliling, untuk itu beberapa kegiatan yang sudah berjalan merupakan kolaborasi antara POMG (Persatuan Orang Tua Murid dan Guru) dan sekolah, di mana POMG mendukung secara tenaga maupun sebagian keuangan yang dikelola, setiap kegiatannya akan ada uang yang dikeluarkan dan harusnya dibukukan secara akuntabel dan konsisten.

Setiap organisasi itu harus bisa memanage organisasi nya dengan baik, seperti memanage 
administrasi berupa dokumentasi dan kegiatan, memanage keuangan yang akuntabel, memanage SDM yang ada di organisasi tersebut. Persoalan yang dihadapi oleh Mitra yaitu Komite Persatuan Orang Tua Murid dan Guru sebagai berikut:

1. Mitra masih memiliki masalah manajemen administrasi seperti visi, misi, tugas dan wewenang dari kepengurusan, hak dan kewajiban kepengurusan. Contohnya belum memiliki buku pedoman/SOP yang jelas atas berdirinya POMG (kepengurusan sebelumnya belum mendokumentasikan secara fisik ataupun soft file).

2. Kegiatan pengelolaan sangat diperlukan dalam berbagai bidang kehidupan. Suatu kegiatan pengelolaan dilakukan baik oleh personal maupun kelompok.

Menurut Tatang M. Amirin, dkk (2010:8) menyatakan bahwa: Manajemen bukan sekedar menyelenggarakan atau melaksanakan sesuatu melainkan menyelenggarakan atau melaksanakan dengan lebih baik, yaitu dengan ditata dan diatur. Penataan pengaturan itulah yang dalam bahasa Indonesia kemudian disebut dengan pengelolaan". Menurut Mulyono (2009: 16) "Pengelolaan adalah proses pencapaian tujuan melalui kegiatan-kegiatan dan kerja sama orang lain". Sedangkan menurut Stoner yang diterjemahkan oleh Handoko (2011:2) bahwa manajemen adalah proses perencanaan, pengorganisasian, pengarahan dan pengawasan usaha-usaha para anggota organisasi dan penggunaan sumber daya-sumber daya organisasi lainnya agar mencapai tujuan organisasi yang telah ditetapkan.

Sistem pembukuan administrasi keuangan secara akuntabel dari POMG. Karena mereka tidak selalu mencatat apa yang menjadi pemasukan dan pengeluaran dari pengelolaan keuangan POMG. Jikapun ada catatan merupakan catatan yang tidak rapi dan tidak tersistem ataupun masih berpa tulisan manual.

Biaya (cost) merupakan istilah yang secara umum berkaitan erat dengan administrasi keuangan. Biaya (cost) dalam Kamus Besar Bahasa Indonesia (KBBI) telah diartikan sebagai uang yang dikeluarkan untuk mengadakan, mendirikan, melakukan sesuatu. Mulyono dalam Mei Hidayati (2012) mendefinisikan biaya sebagai sebagai jumlah uang yang disediakan atau dialokasikan dan digunakan atau dibelanjakan untuk terlaksananya berbagai fungsi atau kegiatan guna mencapai suatu tujuan dan sasaran-sasaran dalam rangka proses manajemen.

Pengelolaan dalam Kamus Besar Bahasa Indonesia (KBBI) diartikan sebagai proses yang memberikan pengawasan pada semua hal yang terlibat dalam pelaksanaan kebijaksanaan dan pencapaian tujuan. Istilah pengelolaan berasal dari kata manajemen atau administrasi. Hal tersebut seperti yang dikemukakan oleh Husaini Usman (2004:3) dalam Mei Hidayati (2012) yang mengandung makna to control yang artinya mengatur dan mengurus.

Akuntabilitas merupakan istilah yang berasal dari kata account yang berarti catatan atau laporan dan ability yang berarti kemampuan. 
Akuntabilas (accountability) secara umum dapat diartikan suatu bentuk pertanggung jawaban. Organisasi yang accountable adalah organisasi yang mampu menyajikan informasi secara terbuka mengenai keputusan-keputusan yang telah diambil dan memungkinkan pihak luar mereview inforamsi tersebut, serta bila dibutuhkan harus ada kesediaan untuk mengambil tindakan kreatif (Sutama, 2006).

Pertanggung jawaban kebijakan dan aturan-aturan yang dibuat oleh sekolah tentunya harus sesuai dengan perencanaan yang ditetapkan. Perencanaan yang sudah ditetapkan akan menjadi dasar untuk membangun prinsip akuntabilitas. Seperti yang dikemukakan oleh Surya Darma (2007) yang dikutip oleh Sutedjo (2009) bahwa ada tiga pilar utama yang menjadi prasyarat terbangunnya akuntabilitas, yaitu: adanya transparansi para penyelenggara sekolah dengan menerima masukan dan mengikutsertakan berbagai komponen dalam mengelola sekolah, Adanya standar kinerja di setiap institusi yang dapat diukur dalam melaksanakan tugas, fungsi dan wewenangnya, Adanya partisapasi untuk saling menciptakan suasana kondusif dalam menciptakan pelayanan masyarakat dengan prosedur yang mudah, biaya yang murah dan pelayanan yang cepat.

Dalam pengabdian ini mitra akan didampingi secara bertahap dalam pemberian materi dan pelatihan sistem pembukuan secara akuntabel dalam pembuatan laporan pemasukan dan pengeluaran keuangan. Karena dengan mereka membuat pencatatan yang baik untuk administrasi keuangan akan berdampak pada transparansi keuangan kepada para orang tua yang selama ini memberikan iuran bulanan. Dan harapannya setelah pembukuan secara akuntabel berjalan dengan baik, hal ini konsisten dilakukan baik kepengurusan saat ini ataupun selanjutnya. Organisasi yang accountable adalah organisasi yang mampu menyajikan informasi secara terbuka mengenai keputusan-keputusan yang telah diambil dan memungkinkan pihak luar mereview inforamsi tersebut, serta bila dibutuhkan harus ada kesediaan untuk mengambil tindakan kreatif (Sutama, 2006).

Berdasarkan uraian masalah yang dihadapi oleh mitra, maka disepakati bahwa masalah utama yang dihadapi oleh mitra adalah manajemen administrasi yang tidak memiliki dokumentasi yang terstruktur dan sistem pembukuan belum secara akuntabel, selain yang diharapkan akuntabel nantinya harus konsiten.

Keberhasilan Pengabdian ini merupakan dukungan pertisipasi dari Mitra, adapun beberapa bentuk partisipasi tersebut sebagai berikut: a. berkoordinasi secara aktif selama kegiatan pengabdian, $b$. mendukung secara maksimal dan proaktif dalam kegiatan pengabdian, c. memberikan data usaha yang diperlukan selama kegiatan pengabdian, d. memberikan masukan tentang hal apa saja yang diperlukan mitra.

Permasalahan yang sudah diuraikan dibagian sebelumnya yaitu manajemen administrasi yang tidak memiliki dokumentasi yang terstruktur dan sistem pembukuan belum secara akuntabel dan konsisten sebagai berikut: 
1. Membantu mitra dalam hal managemen administrasi yaitu dokumentasi terkait kegiatan keuangan ataupun non keuangan. Supervisi kepengurusan sebelumnya yang kurang maksimal dan tidak adanya dokumentasi secara fisik ataupun soft file terkait SOP POMG maupun kegiatan-kegiatan yang sudah dilakukan dalam program kerja.

2. Dalam kegiatan pengabdian mitra akan dibimbing bagaimana caranya mendokumentasikan kegiatan-kegiatan yang sudah dilakukan, membuat SOP yang belum ada dokumennya tapi secara praktek dilapangan sudah dijalankan. Pengabdian Kepada Masyarakat ini akan ada keberlanjutan terus menerus agar POMG menjadi organisasi yang lebih baik di sekolah tersebut. Pengelolaan keuangan atas pemasukan dan pengeluaran belum dilakukan yang sehingga ini kurang baik dalam memanage keuangan. Tidak selalu mencatat apa yang menjadi pemasukan dan pengeluaran dari pengelolaan keuangan POMG sehingga tidak memiliki bukti secara administrasi karena kemungkinan kurangnya supervise yang baik.

\section{METODE}

Kegiatan Pengabdian Kepada Masyarakat pada Playgroup dan Kindergarten Little Bee House Pamulang, Keberadaan Little Bee
House yang memiliki konsep sekolah "home me”, salah satu diantara sekolah yang berada di Komplek Permata Pamulang Blok I 6 / 18, Rawakalong, Tangerang Selatan, Indonesia. Kegiatan ini dilakukan pada tanggal 13-15 Oktober 2019. Dan kegiatan ini dihadiri Pengurus Komite POMG dan sebahagian orang tua yang terlibat.

Penerapan metode dalam melakukan pengabdian sebagai berikut:

1. Metode yang akan dilakukan pada kegiatan pengabdian di organisasi POMG adalah melakukan pendampingan dalam membekali mitra bagaimana caranya mendokumentasikan kegiatankegiatan yang sudah dilakukan, membuat SOP yang belum ada dokumennya tapi secara praktek dilapangan sudah dijalankan.

2. Melakukan pendampingan dalam hal pengolahan keuangan atas pemasukan dan pengeluaran. Sistem pembukuan yang akuntabel akan dibimbing detail dengan cara memberikan materi, lalu langsung pelatihan dengan cara praktek dengan alat bantu seperti buku besar, penggunakan komputer/laptop untuk menyusun atau membuat catatan atas laporan keuangan secara akuntabel.

Kegiatan ini dilakukan di indoor dan outdoor, tujuan diadakan di outdoor agar peserta dari Little Bee House bisa berbaur 
dengan alam sehingga materi yang disampaikan oleh pengabdi bisa lebih mudah dipahami dan menjalin silaturahmi. Adanya bazar yang diadakan oleh POMG di hari pengabdian dapat langsung mempraktekkan dalam pengolahan keuangan yang baik.

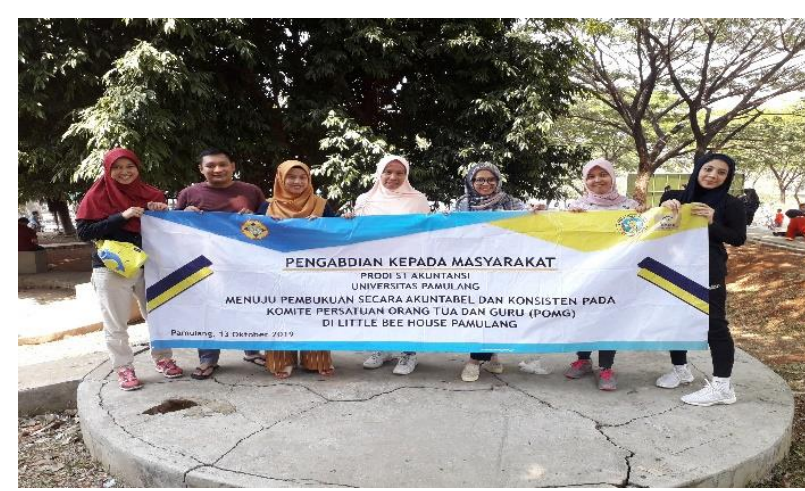

Gambar 1. Bersama Pengurus Utama POMG

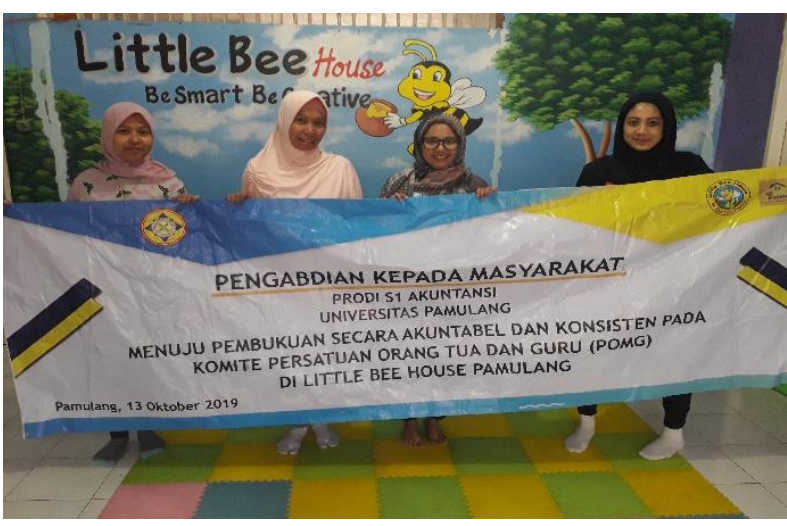

Gambar 2. Bersama Ibu Chairiah Hayatun Nufus, S.Pd (Kepsek)

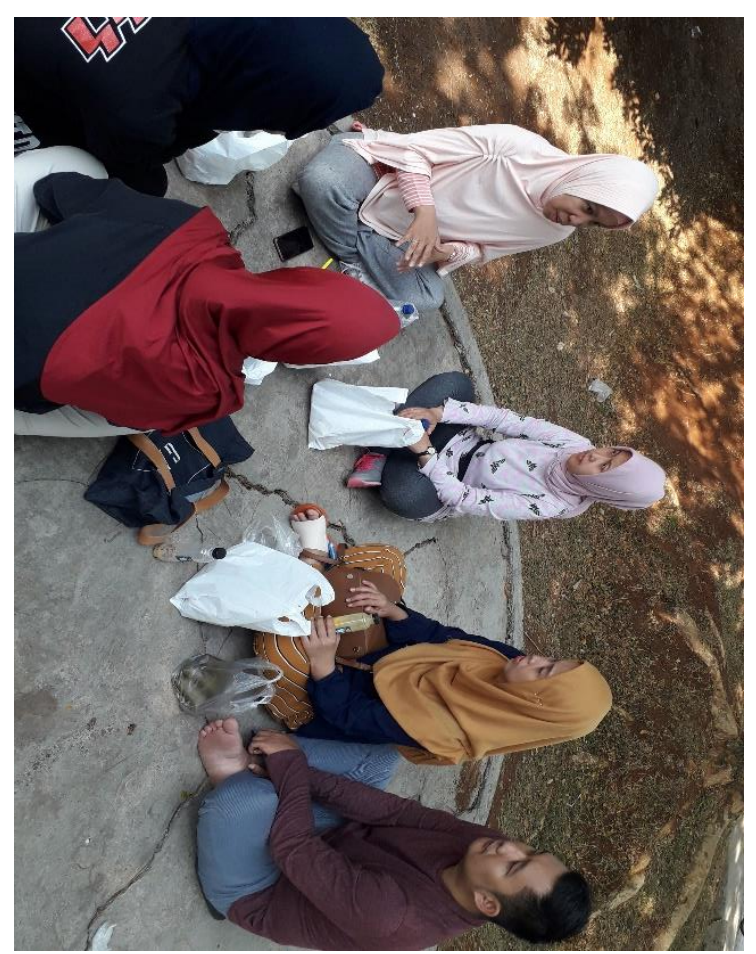

Gambar 3. Penjelasan terkait materi

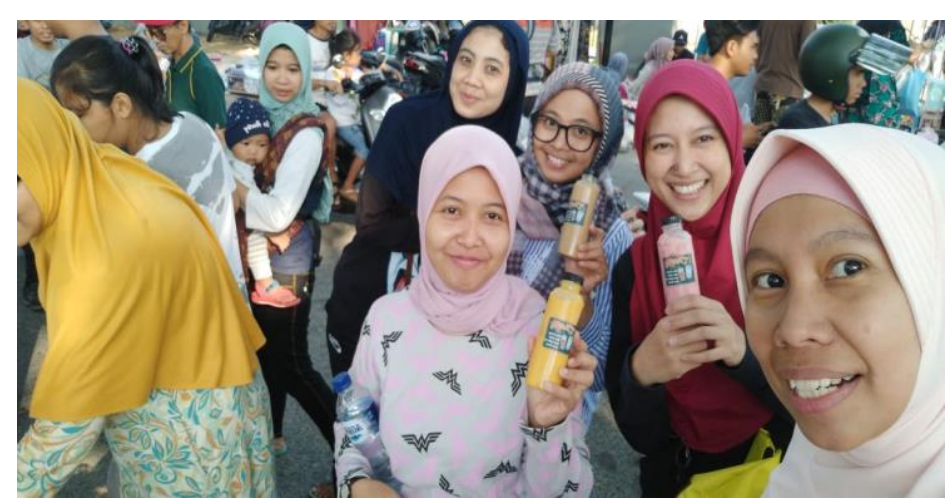

Gambar 4. Hasil dari produk Bazar dan dijadikan kasus dalam materi pengabdian.

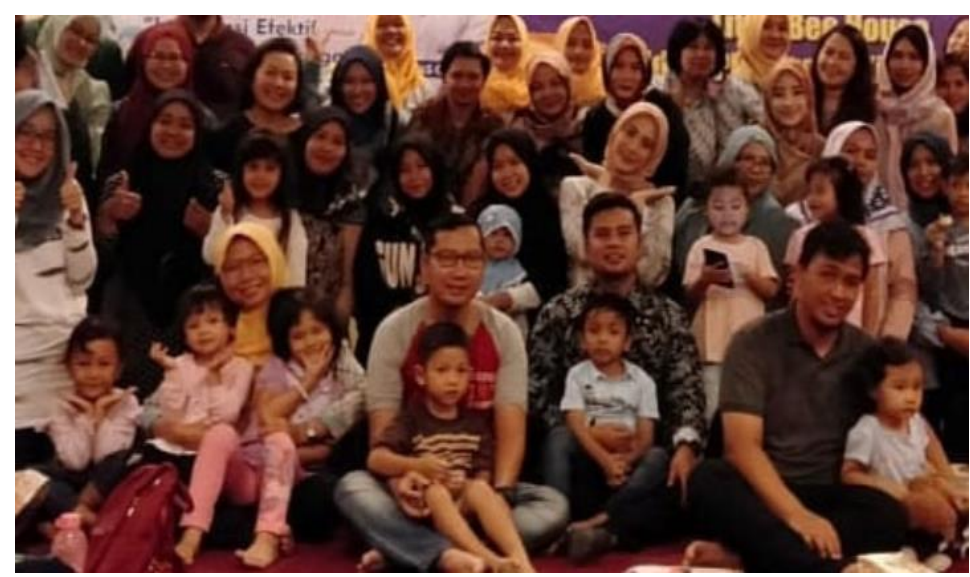

Gambar 5. Bersama beberapa guru dan para orang tua murid. 


\section{HASIL DAN PEMBAHASAN}

Hasil dan pembahasan pengabdian masyarakat pada periode ini dapat dijelaskan dalam bagian ini.

Dalam penerapan metode yang dilakukan dalam pengabdian bahwa:

1. Pengabdi melakukan pendampingan dalam membekali mitra bagaimana caranya mendokumentasikan kegiatankegiatan yang sudah dilakukan, membuat SOP yang belum ada dokumennya tapi secara praktek dilapangan sudah dijalankan. Selama POMG berdiri sejak empat tahun yang lalu sebenarnya proses perbaikan telah dilakukan oleh komite POMG (pengurus yang bergantian), hanya saja dalam hal dokumentasi baik hard file dan soft file belum dilakukan secara efektif dan konsisten. Pengabdi dan narasumber dalam kegiatan ini memberikan edukasi seperti mengggunakan ruang yang disediakan untuk menyimpan file dalam binder, soft file dalam google drive dan sejenisnya.

2. Pengabdi dan Narasumber pendampingan dalam hal pengolahan keuangan atas pemasukan dan pengeluaran. Sistem pembukuan yang akuntabel akan dibimbing detail dengan cara memberikan materi, lalu langsung pelatihan dengan cara praktek dengan alat bantu seperti buku besar, penggunakan komputer/laptop untuk menyusun atau membuat catatan atas laporan keuangan secara akuntabel.
Materi dalam tahap ini masih dalam bentuk teori dan praktek sederhana dengan menggunakan buku, input dalam excel di laptop dan memberikan pilihan aplikasi yang ada di playstore (aplikasi ini akan dipraktekan detail periode Pengabdian selanjutnya).

\section{KESIMPULAN DAN SARAN}

Kesimpulan

Dari paparan yang sudah kami bahas diatas, berikut adalah kesimpulan yang dapat dipaparkan:

1. Butuh fasilitas/aplikasi yang memadai dalam menyimpan atau memanage dokumen, SOP yang belum ada secara fisik (namun secara praktek sudah dijalankan) sebaiknya konsisten dalam penerapannya dan di simpan dalam file (akan berguna untuk pengurus POMG selanjutnya).

2. Pembukuan yang diterapkan sebelumnya menggunakan buku dengan tulisan tangan, padahal pendidikan pangurus POMG rata-rata sudah tingkat strata 1, hingga pendampingan cara pembukuan dengan soft file seperti menggunakan excel atau aplikasi yang ada di playstore yang diberikan oleh pengabdi sangat berguna untuk pembukuan modern dan konsisten. 


\section{Saran}

Berdasarkan hasil pengabdian kepada komite POMG Little Bee House Pamulang bahwa perlu diberikan pelatihan berkelanjutan terkait pengelolaan keuangan dan pembukuan

\section{REFERENSI}

Eka Prihatin. (2011). Teori Administrasi Pendidikan. Bandung: Alfabeta.

Hani Handoko. (2011). Manajemen Edisi 2. Yogyakarta: BPFE.

Ibrahim Bafadal. (2014). Manajemen Perlengkapan Sekolah Teori dan Aplikasinya. Jakarta: Bumi Aksara

Mulyono. (2009). Manajemen Administrasi dan Organisasi Pendidikan. Jakarta: ArRuzz Media. PT. Raja Grafindo Persada.

Mulyono (2010) dalam Mei Hidayati (2012), Toni vitoria 2014, Transparansi dan Akuntabilitas pengelolaan dana pendidikan di SMK Muhammadiyah Prambanan,http://eprints.uny.ac.id/423 56/1/Tomi\%20Viktoria\%20085182440 14.pdf.

Siswanto. (2010). Pengantar Manajemen. Jakarta: Bumi Aksara.

Safwirdi. (2005). Analisis, Pelaporan yang akuntabel dan konsiten dan manage dokumen hard file dan soft file dengan aplikasi/fasilitas yang memadai, sehingga kinerja dari tim komit akan lebih baik lagi ke depannya.

Keuangan Sektor Publik untuk Pengukuran Kinerja, Transparansi Akuntabilitas Publik dan Good Governance (Studi Kasus pada Pemerintah Daerah Tingkat II Daerah Istimewa Yogyakarta). Universitas Gajah Mada.

Sukirman S, Indaryani M. Strategi Pemberdayaan Usaha Kecil Menuju Kemandirian Usaha dengan Menerapkan Manajemen Profesional, Ilmu Manajemen, 2014, 4(1), 13-26.

Sutama, I. K., R. Dharsana, I.G.M. Budiarsana dan T. Kostaman. 2002. Sinkronisasi Birahi dengan Larutan Komposit Testosteron, Oestradiol dan Progesteron (TOP) pada Kambing Peranakan Etawah. JITV, 7(2): 110115.

Tatang M. Amirin, dkk. (2010). Manajemen Pendidikan. Yogyakarta: UNY. Press 